\title{
Profile of microRNAs associated with aging in rat liver
}

\author{
SHIMA MIMURA ${ }^{1}$, HISAKAZU IWAMA ${ }^{2}$, KIYOHITO KATO ${ }^{1}$, KEI NOMURA ${ }^{1}$, MITSUYOSHI KOBAYASHI ${ }^{1}$, \\ HIROHITO YONEYAMA ${ }^{1}$, HISAAKI MIYOSHI ${ }^{1}$, JOJI TANI ${ }^{1}$, ASAHIRO MORISHITA ${ }^{1}$, TAKASHI HIMOTO ${ }^{1}$, \\ AKIHIRO DEGUCHI ${ }^{1}$, TAKAKO NOMURA ${ }^{1}$, TEPPEI SAKAMOTO ${ }^{1}$, KOJI FUJTAA ${ }^{1}$, EMIKO MAEDA ${ }^{1}$, \\ KUNIHIKO IZUISHI $^{3}$, KEIICHI OKANO ${ }^{2}$, YASUYUKI SUZUKI ${ }^{2}$ and TSUTOMU MASAKI $^{1}$
}

Departments of ${ }^{1}$ Gastroenterology and Neurology, ${ }^{2}$ Signal Transduction Sciences, and ${ }^{3}$ Gastroenterological Surgery, Faculty of Medicine, Kagawa University, Kagawa 761-0793, Japan

Received January 4, 2014; Accepted July 30, 2014

DOI: $10.3892 /$ ijmm.2014.1892

\begin{abstract}
Recent studies suggest that small non-coding microRNAs (miRNAs or miRs) play an important role in the regulation of genes involved in various cellular and developmental processes. However, the expression of miRNAs during the aging process remains largely unknown. The aim of the present study was to analyze miRNA expression profiles in rat livers during the aging process. The livers of male Wistar rats at different stages of development (fetal, aged 3 days, and $1,2,4,8$ and 36 weeks of age) were used. Total RNA was extracted from the livers. We analyzed the expression levels of 679 rat miRNA probes. In addition, immunohistochemical staining for proliferating cell nuclear antigen (PCNA) was performed. Several up- and downregulated miRNAs were identified in the rat livers at 7 different fetal developmental stages and at 36 weeks of age. We observed the upregulation of miR-29a, miR-29c, miR-195 and miR-497, whereas miR-301a, miR-148b-3p, miR-7a, miR-93, miR-106b, miR-185, miR-450a, miR-539 and miR-301b were downregulated in the aging rat livers. The number of PCNA-positive hepatocytes was decreased with age. In conclusion, our findings suggest that these up- and downregulated miRNAs play an important role in aging by regulating cell cycles that are involved in liver senescence. Further investigation is required to reveal additional target genes of the miRNAs expressed in the liver and the roles of miRNAs in the developmental process of aging in the liver.
\end{abstract}

Correspondence to: Dr Shima Mimura, Department of Gastroenterology and Neurology, Faculty of Medicine, Kagawa University, 1750-1 Ikenobe, Miki-cho, Kita-gun, Kagawa 761-0793, Japan

E-mail: shimamimura@hotmail.com

Abbreviations: miRNA, microRNA; PCNA, proliferating cell nuclear antigen; ABC, avidin-biotin complex; SDS-PAGE, sodium dodecyl sulfate-polyacrylamide gel electrophoresis; HGF, hepatocyte growth factor

Key words: microRNA, fetal liver, cell cycle, aging

\section{Introduction}

MicroRNAs (miRNAs or miRs) are small non-coding RNAs that regulate both the mRNA and the protein expression of target genes (1). miRNAs play a crucial role in the regulation of genes involved in the control of development, cell proliferation, apoptosis and stress response (2). The expression profile analysis of miRNAs is essential for understanding the complex regulation of gene expression that involves miRNAs in addition to characterizing miRNAs themselves (3). Some miRNAs exhibit tissue-specific expression (4). The liver is a crucial organ in which miRNAs may be involved in the regulation of hepatocyte growth and development. The expression profiles of miRNAs in fetal liver are different from those in the adult liver; fetal miRNA expression has shown specificity in the developmental stage (5). Global gene and miRNA expression in embryonic and adult human livers has been analyzed, revealing multiple regulated genes and demonstrating a change in the expression patterns during the developmental process (6). A number of studies have focused on accelerated aging and miRNAs, such as miRNAs in the aging mouse brain $(3,7)$. Previous studies have analyzed the expression of miRNAs in the livers of young and elderly humans (6) and rats (8), as well as in mice with delayed aging $(9,10)$. However, the association between miRNA expression and the aging of the liver remains poorly understood (11).

In the present study, we identified a gradual up- and downregulation of miRNAs in rats at 7 different developmental stages (fetal to 36 weeks old). We found that miR-29a, miR-29c, miR-195 and miR-497 were gradually upregulated and that miR-301a, miR-148b-3p, miR-7a, miR-93, miR-106b, miR-185, miR-450a, miR-539 and miR-301b were gradually downregulated in livers as the rats aged.

\section{Materials and methods}

Animals. Inbred Wistar rats were bred under specific pathogen-free conditions at the Institute for Animal Experimentation of the Kagawa University School of Medicine Kagawa, Japan. Eight male Wistar rats from the ages of postnatal day 3, and post-natal week 1, 2, 4, 8 and 36 were used in this study. Eight fetal livers were also obtained from pregnant 
rats at day 20. We performed hepatectomy under ether anesthesia. For immunohistochemistry, small sections of the liver tissue were preserved in $10 \%$ formalin. The remaining sections of the liver tissue were rapidly placed in liquid nitrogen, transferred individually to pre-weighed tubes containing RNAlater (Ambion, Tokyo, Japan) and stored at $-80^{\circ} \mathrm{C}$ until analysis.

RNA isolation. The frozen tissue samples were thawed on ice and dissolved in TRIzol reagent (Invitrogen Life Technologies, Carlsbad, CA, USA). Total RNA was extracted from the tissues using an miRNeasy Mini kit (Qiagen, Tokyo, Japan) according to the manufacturer's instructions. Briefly, $700 \mu \mathrm{l}$ of TRIzol reagent containing samples was mixed vigorously with $140 \mu 1$ of chloroform, incubated at room temperature for $3 \mathrm{~min}$, followed by centrifugation at $12,000 \mathrm{x} \mathrm{g}$ for $15 \mathrm{~min}$ at $4^{\circ} \mathrm{C}$. The upper aqueous phase was transferred to another tube containing $525 \mu \mathrm{l}$ of $100 \%$ ethanol. The mixture was loaded into RNeasy Mini columns, followed by serial washing with solutions provided with the kit. Finally, RNA was collected into RNase-free water for further experiments. All RNA samples used in this study showed A260/280 ratios between 2.0 and 2.1. The integrity of RNA was determined using a NanoDrop 2000 spectrophotometer (Thermo Scientific, Rockford, IL, USA). The quality of total RNA was determined using the RNA Nano 6000 chips on an Agilent 2100 Bioanalyzer (Agilent Technologies Inc., Osaka, Japan), and all RNA samples used for microarray analyses had RIN values $>8.2$. These RNA samples were stored at $-80^{\circ} \mathrm{C}$.

miRNA arrays. Total RNA was labeled with Hy3 dye using the array labeling kit (Exiqon, Vedbæk, Denmark). Total RNA $(2 \mu \mathrm{g})$ was incubated with a spike for $30 \mathrm{~min}$ at $37^{\circ} \mathrm{C}$ and then at $95^{\circ} \mathrm{C}$ for $5 \mathrm{~min}$. Hy3 dye and labeling enzyme were added to the samples. The enzyme was then heat-inactivated at $16^{\circ} \mathrm{C}$ for $1 \mathrm{~h}$ and $65^{\circ} \mathrm{C}$ for $15 \mathrm{~min}$, protected from light and then received an addition of hybridization buffer. The sample was loaded onto the arrays by capillary force using 3D-Gene miRNA oligo chips (version 16; Toray Industries, Inc., Kanagawa, Japan). The chips enabled the examination of the expression of 679 miRNAs printed in duplicate spots. The arrays were incubated at $32^{\circ} \mathrm{C}$ for $16 \mathrm{~h}$, then briefly washed in a $30^{\circ} \mathrm{C}$ wash buffer solution (0.5X SSC, $0.1 \%$ SDS), rinsed in wash buffer solution (0.2X SSC, $0.1 \%$ SDS) followed by a wash in another buffer solution (0.05X SSC), according to the manufacturer's instructions (Toray Industries, Inc.). The arrays were spun for $1 \mathrm{~min}$ at 1,000 rpm for drying, followed by immediate scanning using a Toray 3D-Gene 3000 miRNA microarray scanner (Toray Industries, Inc.). The relative expression level of each miRNA was calculated by comparing the average signal intensities of the valid spots with their mean value throughout the microarray experiments following normalization to their adjusted median values.

Heatmap. To illustrate the alterations in the expression levels of the 13 upregulated or downregulated miRNAs, we created a heatmap in which each cell represents the expression level of each of the 13 miRNAs for each of 8 individual rats at different stages of development, namely the fetal period, at post-natal day 3 and post-natal week 1, 2, 4, 8 and 36 . The heatmap was color-coded according to the log2-transformed expression level. The center level of the color code is set as the median value over all of the values used in the heatmap. Briefly, in the heatmap, white color represents mean values, red indicates gains and blue represents losses.

Immunohistochemistry. The avidin-biotin complex (ABC) immunohistochemical method was used. Following formalin fixation, the tissues were dehydrated in a graded series of ethanol and embedded in paraffin. The serial sections were mounted onto glass slides. Immunohistochemical staining for proliferating cell nuclear antigen (PCNA) was performed using the following procedure: the sections were deparaffinized, hydrated and quenched for endogenous peroxidase with $0.3 \%$ hydrogen peroxide in PBS at room temperature for $30 \mathrm{~min}$. The sections were permeabilized in PBS with $0.3 \%$ polyoxyethylene (10) octyl phenyl ether (Triton X-100) (Wako, Osaka, Japan) for $1 \mathrm{~h}$ before quenching the endogenous peroxidase activity. The sections were then incubated overnight at room temperature with a mouse anti-PCNA antibody (1:100 dilution; Dako, Glostrup, Denmark). Antibody binding was detected using a Vectastain Elite ABC kit (Vector Laboratories, Burlingame, CA, USA) and 3,3'-diaminobenzidine as a chromogen. After staining, all sections were counterstained with Mayer's hematoxylin. The specificity of immunostaining was examined using non-immune mouse $\mathrm{IgG}$ as a negative control for the primary antibody. Images were captured using an Olympus BX51 microscope and Olympus DP72 camera (Olympus, Tokyo, Japan). The nuclear labeling index for the PCNA-positive cells (positive nuclei/total counted) was determined by evaluating at least 500 hepatocytes at random in the microscopic field by 2 observers (T. Masaki and S. Mimura).

Western blot analysis. Frozen liver tissue samples were homogenized in a protein extraction solution (PRO-PERP ${ }^{\text {TM }}$; Intron Biotechnology, Inc., Gyeonggi, Korea), and cell lysis was then induced by incubating the samples for 20 min on ice. The samples were prepared by centrifugation at 13,000 rpm for $5 \mathrm{~min}$ at $4^{\circ} \mathrm{C}$. The supernatant was then collected. The protein concentration was measured by a dye-binding protein assay performed according to the Bradford method (12). Sodium dodecyl sulfate-polyacrylamide gel electrophoresis (SDS-PAGE) was performed according to the method of Laemmli (13), and western blot analysis was performed as previously described by Towbin et al (14) using anti- $\beta$-actin monoclonal antibody (Sigma-Aldrich; A5442, used at 1:3,000) and cyclin D1 (Thermo Fisher Scientific, Waltham, MA, USA; RB-9041, used at 1:1,000) as primary antibodies and horseradish peroxidase-inked anti-mouse and anti-rabbit IgG secondary antibodies (GE Healthcare UK, Buckinghamshire, UK; used at 1:2,000).

\section{Results}

Quality assessment of the total RNA of the sample using a miRNA array chip. Total RNA $(20 \mu \mathrm{l})$ from all liver tissues used in this study was loaded into each lane, and the bands of $18 \mathrm{~S}$ and $28 \mathrm{~S}$ ribosomal RNA in the gel were detected using the 2100 Bioanalyzer (Fig. 1). Based on these results, RNA samples extracted from various liver tissues were shown to be of adequate quality. 


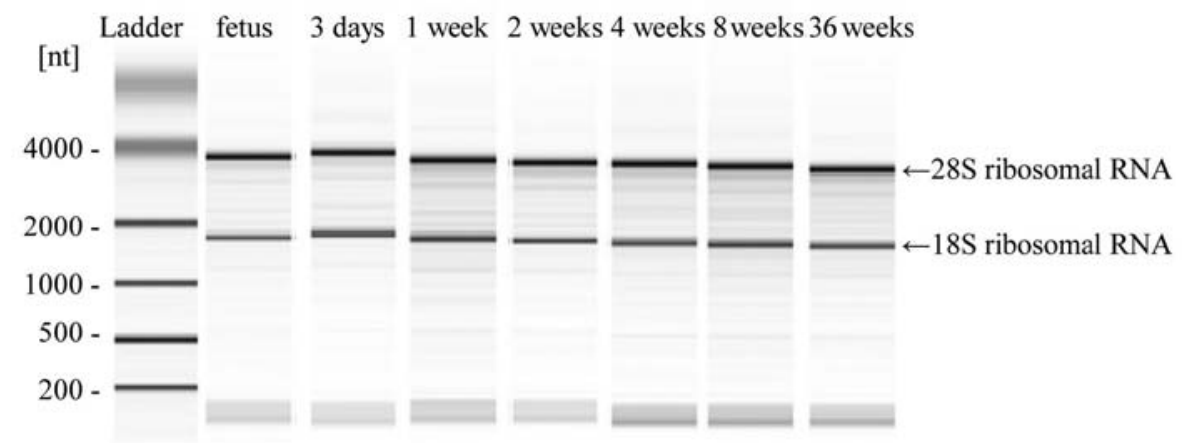

Figure 1. Quality of total RNA of developmental liver tissues using microRNA (miRNA) array chip. The bands of 18S and 28S ribosomal RNA in the gel were detected using a 2100 Bioanalyzer. Total RNA in all liver tissue samples used in the miRNA chip analysis was of high quality. Equal amounts of total RNA obtained from developmental liver tissues were used for miRNA analysis.
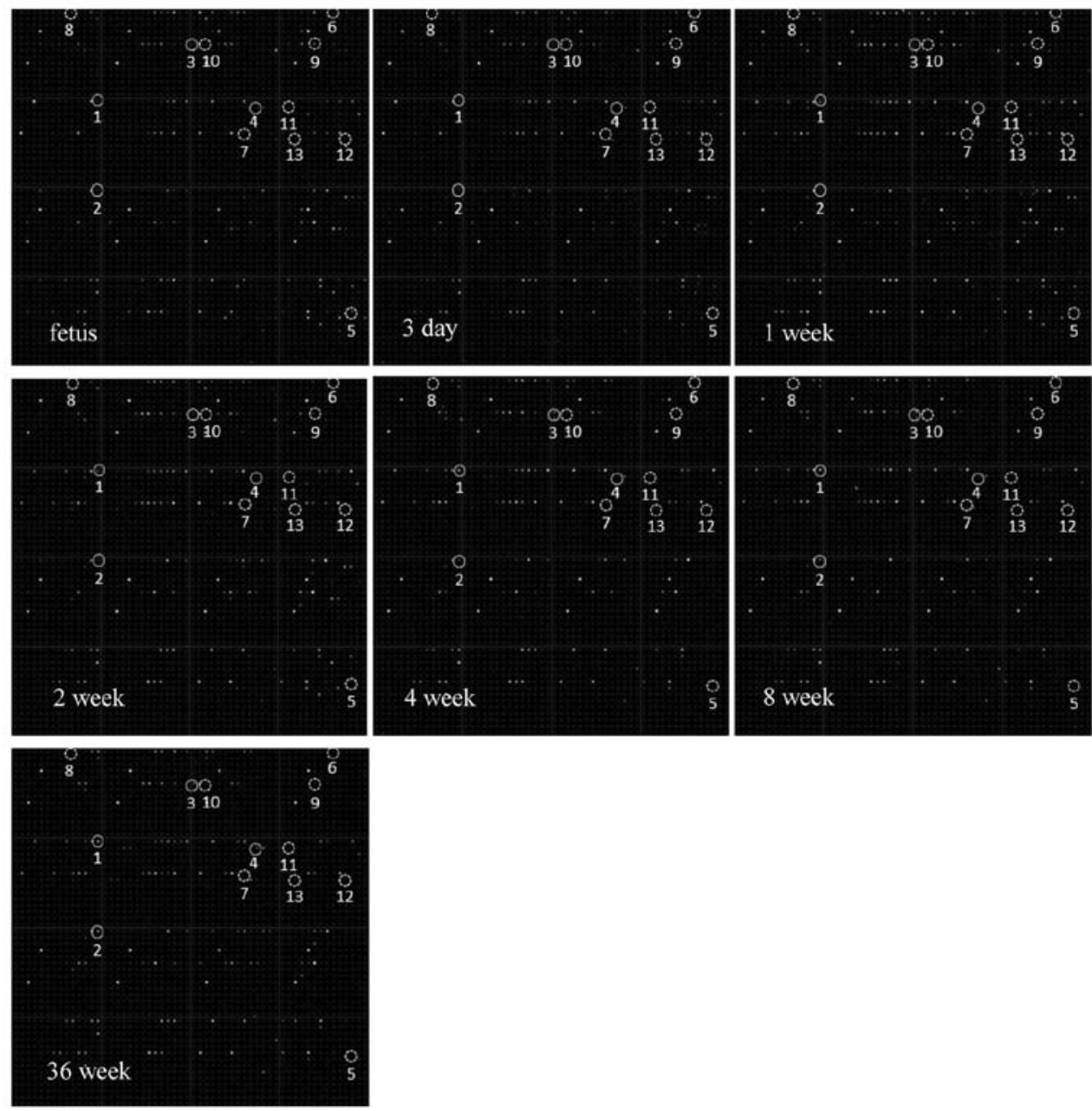

Figure 2. MicroRNA (miRNA) expression in rat livers at 7 different stages of development (fetal, post-natal day 3 and post-natal weeks $1,2,4,8$ and 36) in miRNA chips. Spot numbers 1-4 (1, miR-29a; 2, miR-29c; 3, miR-195; 4, miR-497) were miRNAs upregulated with liver development. Spot numbers 5-13 (5, miR-301a; 6, miR-148b-3p; 7, miR-7a; 8, miR-93; 9, miR-106b; 10, miR-185; 11, miR-450a; 12, miR-539; 13, miR-301b) were miRNAs downregulated with liver development.

Developmental study of miRNA expression in liver tissue. Using a custom microarray platform, we analyzed the expression levels of 679 rat miRNA probes. Four miRNAs were found to be gradually upregulated with age in the rat livers. The 4 upregulated miRNAs were miR-29a (spot no. 1), miR-29c (spot no. 2), miR-195 (spot no. 3) and miR-497 (spot no. 4) (Figs. 2 and 3). By contrast, 9 miRNAs were gradually downregulated. These downregulated miRNAs were miR-301a (spot no. 5), miR-148b-3p (spot no. 6), miR-7a (spot no. 7), miR-93 (spot no. 8), miR-106b (spot no. 9), miR-185 (spot no. 10), 
A
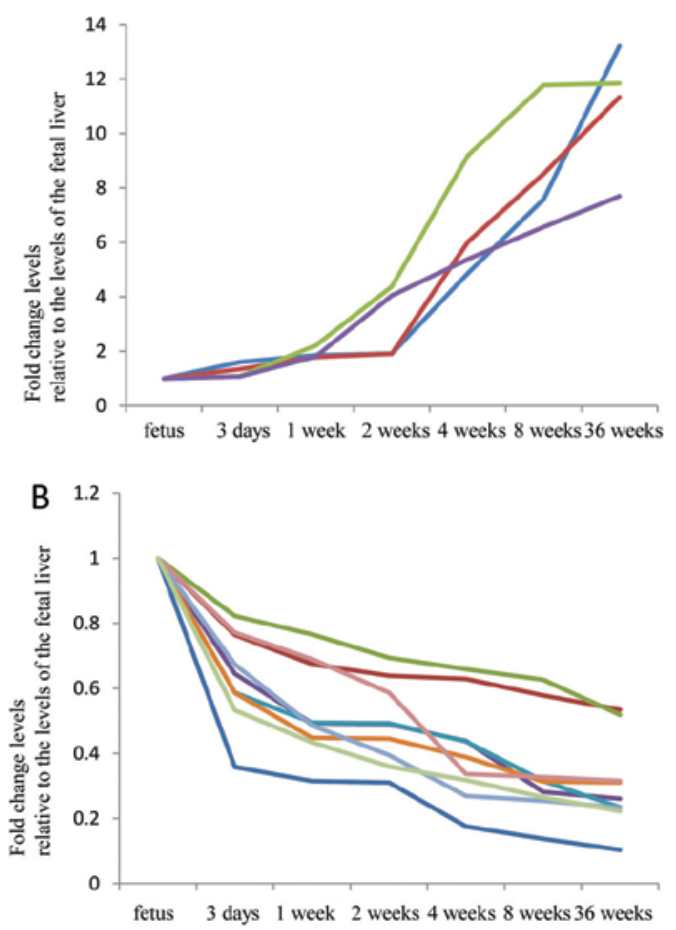

Figure 3. MicroRNA (miRNA) expression analysis. (A) Upregulated miRNAs Fold change levels are reported relative to the levels of the fetal liver. miR-29a, miR-29c, miR-195 and miR-497 upregulation was confirmed. A significant $(p<0.01)$ upregulation was found in the livers of post-natal week 4 and 8 rats for each upregulated miRNA. (B) Downregulated miRNAs. The expression levels of miR-301a and 301b were downregulated by more than half at postnatal day 3 .

miR-450a (spot no. 11), miR-539 (spot no. 12) and miR-301b (spot no. 13). The heatmap (Fig. 4) clearly demonstrates increasing trends for 4 miRNAs and decreasing trends for 9 miRNAs in the expression levels among the age groups. It also showed that the trends in miRNA expression were fairly consistent among individual rats and were constant in both increasing and decreasing directions.

Immunohistochemical study of PCNA in developing livers. The typical immunohistochemical staining pattern of PCNA at various stages of development in the rat livers, including fetal liver (Fig. 5A), post-natal day 3 liver (Fig. 5B), post-natal week 1 liver (Fig. 5C), post-natal week 2 liver (Fig. 5D), postnatal week 4 liver (Fig. 5E), post-natal week 8 liver (Fig. 5F) and post-natal week 36 liver (Fig. 5G). The labeling index of PCNA in the hepatocytes in the developing livers decreased with age (Fig. 5H).

Western blot analysis of aging rat liver. Western blot analysis was used to examine the cell cycle of the aging rat liver by using an antibody against cyclin D1. The cyclin D1 level was hardly detectable in the fetal liver (Fig. 6). However, cyclin D1 was detected in the liver at post-natal day 3 . The highest level was detected in the post-natal week 1 liver and the level slightly decreased with age. The amount of $\beta$-actin (an internal control for protein loading) was almost the same in all age groups.

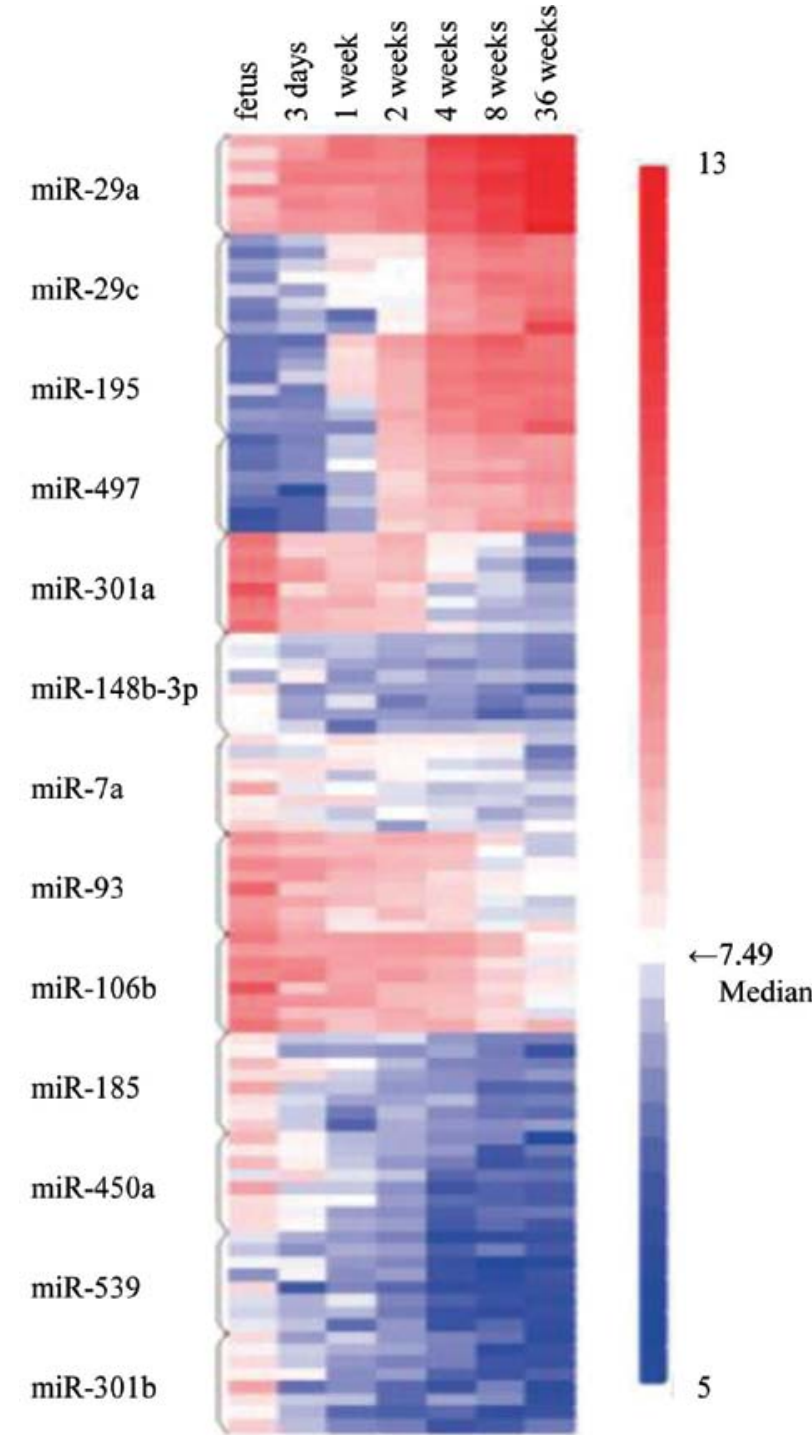

Figure 4. A heatmap showing increasing and decreasing trends of the microRNA (miRNA) expression levels in rats during different stages of development. The expression level of each miRNA for each individual rat is shown for each age group as a color-coded cell. A vertical bar beside the heatmap indicates the scale of the color code of the log2-transformed expression levels. The center level of the color code is set as the median value over all of the values used in the heatmap. White color represents mean values, red indicates gains and blue represents losses.

\section{Discussion}

The dysregulation of miRNA expression may contribute to numerous alterations present in very complex and multifactorial processes, namely, proliferation, differentiation, inflammation, carcinogenesis and aging (11). The profiles of miRNAs have been reported by developmental studies in various organs, such as the brain (15-18), kidneys (19), pancreas (20) and liver $(21,22)$. However, the alterations in miRNA expression in the rat liver during the process of aging remain poorly understood. In the present study, in order to detect miRNAs associated with aging in the rat liver, we investigated miRNAs with a gradually increasing or decreasing expression in the livers of rats at different stages of development. Such miRNAs appear to play an important role in aging. To the best of our 

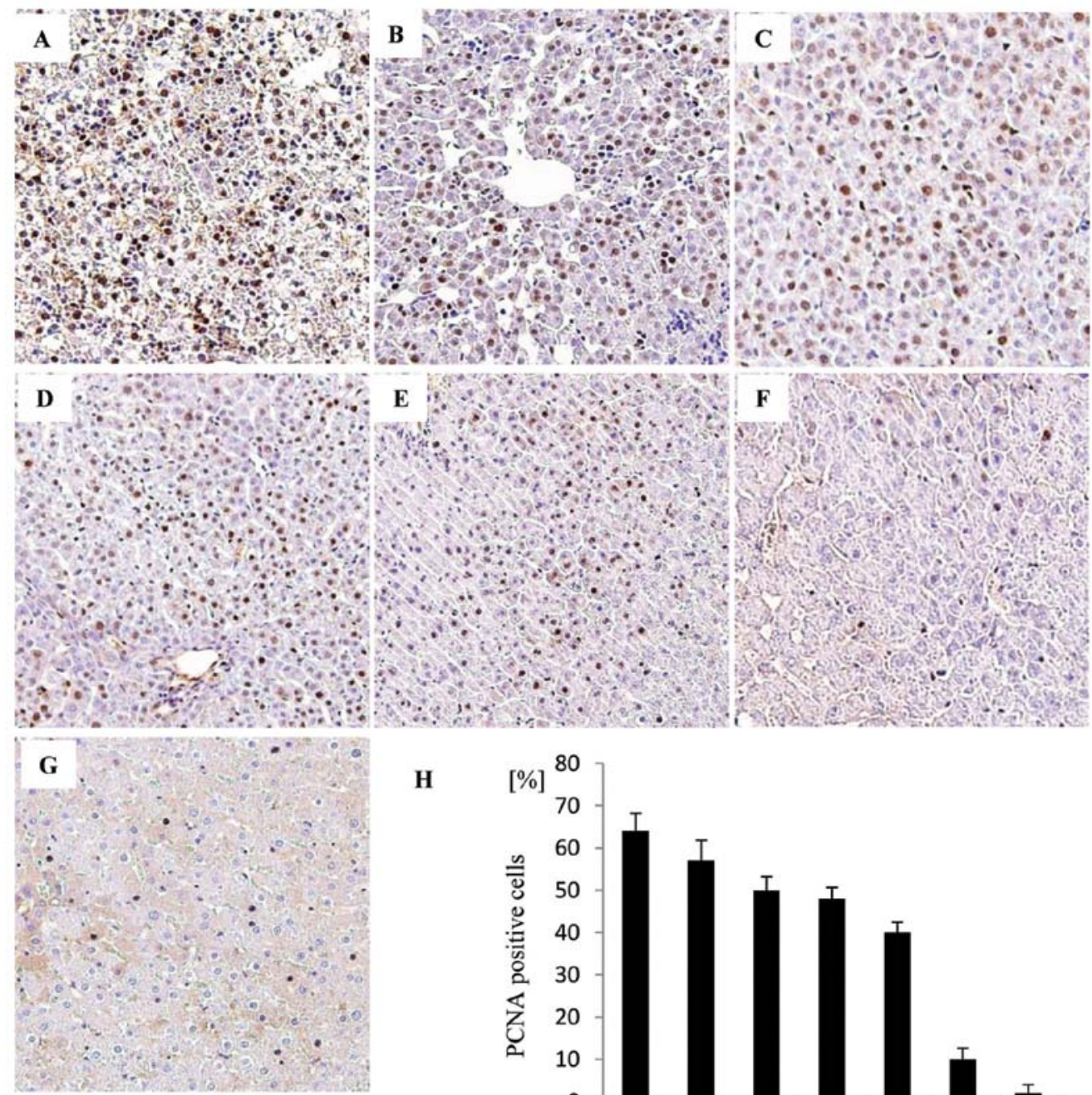

$\mathbf{H}$

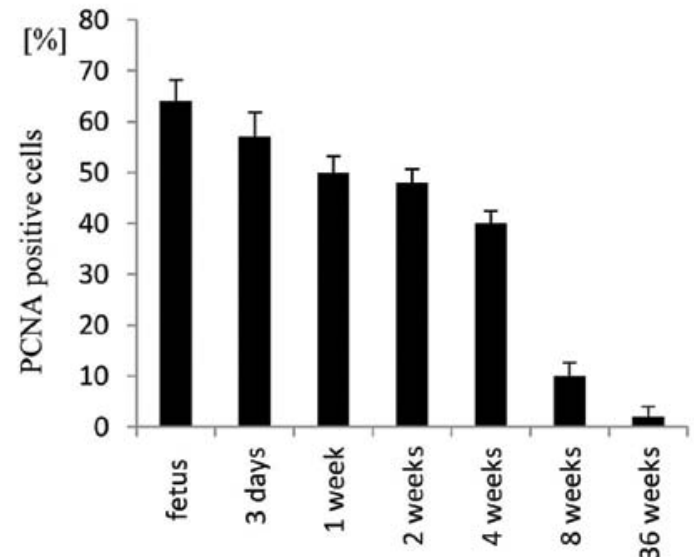

Figure 5. Immunohistochemical analysis of proliferating cell nuclear antigen (PCNA). The immunohistochemical staining pattern of PCNA in various stages of development in the rat livers, including (A) fetal liver, (B) post-natal day 3 liver, (C) post-natal week 1 liver, (D) post-natal week 2 liver, (E) post-natal week 4 liver, (F) post-natal week 8 liver and (G) post-natal week 36 liver. (H) The labeling index of PCNA of the hepatocytes in developing livers decreased with age.

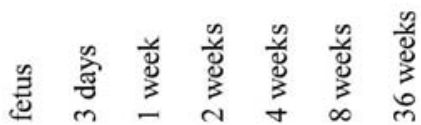

Cyclin D1

$\beta$-actin

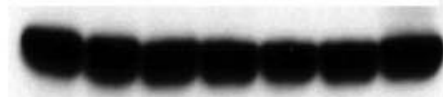

Figure 6. Western blot analysis. The cyclin D1 level was almost undetectable in the fetal liver. However, the cyclin D1 level was detectable in the liver at post-natal day 3. It was detected at the highest level in post-natal week 1 liver, and slightly decreased with age. $\beta$-actin was used as a loading control.

knowledge, to date, no studies have established an association between miRNAs and aging of the liver in a similar manner as we have done.
In the present study, we demonstrated that miR-29a, miR-29c, miR-195 and miR-497 were upregulated with age, whereas miR-301a, miR-148b-3p, miR-7a, miR-93, miR-106b, miR-185, miR-450a, miR-539 and miR-301b were downregulated with age in the rat livers. These data suggest that specific miRNAs are associated with aging in the liver.

miR-29a and miR-29c were upregulated during early development in the liver (rats at post-natal week 4 and 8) and during late development in the liver (post-natal week 36). Notably, the expression levels of miR-29a and miR-29c were $>10$-fold higher in the livers from the 36 -week-old rats than the fetal rat livers. miR-29a and miR-29c have been shown to be age-related in various organs, such as the aorta $(23,24)$, the lungs $(25,26)$, the kidneys (19) and the liver in mice $(21,22)$. The upregulation of miR-29a and miR-29c with age is consistent with a recent report showing an increased expression of miR-29 family members in a model of accelerated aging in mice (11). 
Table I. Chromosomal locations and target genes of the up- and downregulated miRNAs.

\begin{tabular}{|c|c|c|c|}
\hline Name & Genome context & & Target gene (Ref.) \\
\hline $\begin{array}{l}\text { Upregulated } \\
\text { rno-miR-29a }\end{array}$ & 4: 58107760-58107847 [-] & $4 q 22$ & $\begin{array}{l}\text { p53 (11), hepatocyte growth factor }(31), \text { Bcl-2 }(32), \\
\text { nuclear autoantigenic sperm protein }(33), \text { TGF- } \beta 1(34) \\
\text { p42.3 (35), Arpc3 (36), monocarboxylate transporter } 1 \text { (37), } \\
\text { maternally expressed gene } 3(38), \\
\text { Tcl1 (39), DNA methyltransferase } 3(40), \\
\text { phosphatase and tensin homolog }(41)\end{array}$ \\
\hline rno-miR-29c & 13: $110968048-110968135[+]$ & $13 q 27$ & $\begin{array}{l}\text { p53 (11), MCT-1 (37), Bcl-2 (32), TGF- } \beta 1 \text { (34), } \\
\text { tumor necrosis factor } \alpha \text {-induced protein } 3(42), \\
\beta \text {-site APP cleaving enzyme } 1 \text { (43), cyclin E (44) }\end{array}$ \\
\hline rno-miR-195 & 10: $57074170-57074256[+]$ & $10 q 24$ & $\begin{array}{l}\text { Cyclin-dependent kinase } 4(45), \text { Bcl-2 }(46-48), \\
\text { ethanol-mediated inhibition of hepatic sirtuin } 1(47), \\
\text { cyclin E1 (49), cyclin D1 }(50,51), \text { CDK6 }(50), \text { E2F3 }(50,52) \\
\text { Raf-1 (52) }\end{array}$ \\
\hline rno-miR-497 & 10: $57073846-57073914[+]$ & $10 q 24$ & Bcl-2 $(53,54)$, cyclin D2 (54) \\
\hline \multicolumn{4}{|l|}{ Downregulated } \\
\hline rno-miR-301a & 10: $75386838-75386937[+]$ & $10 q 26$ & Plasminogen activator inhibitor-1 (55) \\
\hline rno-miR-148b-3p & & & $\begin{array}{l}\text { AMPK } \alpha 1 \text { (56), ITGA5, ROCK1, PIK3CA/p110 } \alpha, \text { NRAS, } \\
\text { CSF1 (57) }\end{array}$ \\
\hline rno-miR-7a & & & Barx $1(58)$ \\
\hline rno-miR-93 & 12: 17608173-17608259 [-] & $12 q 11$ & $\begin{array}{l}\text { Sirtuin } 1(8), \text { S-transferase } 1 \text { (8), integrin- } \beta 8 \text { (59), } \\
\text { FUS1 (60), p21 (61) }\end{array}$ \\
\hline rno-miR-106b & 12: $17608382-17608463[-]$ & $12 q 11$ & p21 (61-64), RB (65) \\
\hline rno-miR-185 & 11: $84658785-84658864[+]$ & $11 \mathrm{q} 23$ & $\begin{array}{l}\text { DNA methyltransferase } 1 \text { (66), Rho, Cdc42 (67), } \\
\text { Six1 (68) }\end{array}$ \\
\hline rno-miR-450a & X: 139994947-139995037 [-] & $\mathrm{Xq36}$ & DNA methyltransferase 3a (69) \\
\hline rno-miR-539 & 6: 134408917-134408992 [+] & $6 q 32$ & Holocarboxylase synthetase (HCS) $(70,71)$ \\
\hline rno-miR-301b & 11: $85885248-85885325[+]$ & $11 \mathrm{q} 23$ & ТP63 (72) \\
\hline
\end{tabular}

miRNA, microRNA.

Several studies have indicated that the cellular replication capacity (proliferative activity) declines in various tissues and may compromise the immune system during aging (27-29). In addition, the number of senescent cells increases in various tissues with aging (30). Indeed, in this study, we also demonstrated that the expression of PCNA in hepatocytes decreased with age. These data suggest that the number of senescent cells in the liver increased with age.

In the present study, the 4 miRNAs with a gradually upregulated expression (miRNA-29a, miRNA29c, miRNA-195 and miR-497) possess target genes to promote proliferative activity, whereas the 4 miRNAs (miR-148-3p, miR-93, miR-106b and miR-185) whose expression was gradually reduced, possess genes to inhibit proliferative activity, such as tumor suppressor gene and the cyclin-dependent kinase inhibitor, p21WAF1 (Table I). Hepatocyte growth factor (HGF), cyclin E, Cdk4, Cdk6 and cyclin D1 play important roles in the progression of the cell cycle, and their molecules are the targets of upregulated miRNAs (Table I). By contrast, p21 (also known as p21CIP1/WAF1), sirtuin and fused in sarcoma (FUS)1 play important roles in the arrest of the cell cycle, and their molecules are targets of downregulated miRNAs (Table I). Therefore, these data suggest that numerous up- and downregulated miRNAs play an important role in the decline of the proliferative activity of hepatocytes with age.

In conclusion, in the present study, we identified the upregulation of miR-29a, miR-29c, miR-195 and miR-497, and the downregulation of miR-301a, miR-148b-3p, miR-7a, miR-93, miR-106b, miR-185, miR-450a, miR-539 and miR-301b in the rat liver with age. Our data also suggest that important changes in miRNA expression occur during development, and one result of aging is likely to be changes in miRNA expression. Our findings suggest that these up- and downregulated miRNAs play important roles by regulating cell cycles that are related to liver senescence. Further studies are required to clarify additional miRNA targets, as well as the roles of miRNAs in the development of the complex process of aging in the liver. 


\section{Acknowledgements}

We thank Madoka Seguchi, Yuuko Miyawaki, Fuyuko Kokado and Ryoko Unose (Kagawa University) for their excellent technical assistance.

\section{References}

1. Lakner AM, Bonkovsky HL and Schrum LW: MicroRNAs: Fad or future of liver disease. World J Gastroenterol 17: 2536-2542, 2011.

2. Pogribny IP, Tryndyak VP, Boyko A, et al : Induction of microRNAome deregulation in rat liver by long-term tamoxifen exposure. Mutat Res 619: 30-37, 2007.

3. Eda A, Takahashi M, Fukushima T and Hohjoh H: Alteration of microRNA expression in the process of mouse brain growth. Gene 485: 46-52, 2011.

4. Lagos-Quintana M, Rauhut R, Yalcin A, et al: Identification of tissue-specific microRNAs from mouse. Curr Biol 12: 735-739, 2002.

5. Lagos-Quintana M, Rauhut R, Lendeckel W and Tuschl T: Identification of novel genes coding for small expressed RNAs. Science 294: 853-858, 2001.

6. Tzur G, Israel A, Levy A, et al: Comprehensive gene and microRNA expression profiling reveals a role for microRNAs in human liver development. PLoS One 4: 7511, 2009.

7. Li N, Bates DJ, An J, et al: Up-regulation of key microRNAs, and inverse down-regulation of their predicted oxidative phosphorylation target genes, during aging in mouse brain. Neurobiol Aging 32: 944-955, 2011.

8. Li N, Muthusamy S, Liang R, et al: Increased expression of miR-34a and miR-93 in rat liver during aging, and their impact on the expression of Mgst1 and Sirt1. Mech Ageing Dev 132: 75-85, 2011.

9. Bates DJ, Li N, Liang R, et al: MicroRNA regulation in Ames dwarf mouse liver may contribute to delayed aging. Aging Cell 9: $1-18,2010$

10. Maes OC, An J, Sarojini H and Wang E: Murine microRNAs implicated in liver functions and aging process. Mech Ageing Dev 129: 534-541, 2008.

11. Ugalde AP, Ramsay AJ, de la Rosa J, et al: Aging and chronic DNA damage response activate a regulatory pathway involving miR-29 and p53. EMBO J 30: 2219-2232, 2011.

12. Bradford M: A rapid and sensitive method for the quantitation of microgramof protein utilizing the principle of protein-dye binding. Anal Biochem 72: 248-254, 1976.

13. Laemmli UK: Cleavage of structural proteins during the assembly of the head of bactriophage T4. Nature 227: 680-685, 1970.

14. Towbin H, Staehelin T and Gordon J: Electrophoretic transfer of proteins from polyacrylamide gels to nitrocellulose sheets: procedure and some applications. Proc Natl Acad Sci USA 76: 4350-4354, 1976.

15. Aw S and Cohen SM: Time is of the essence: microRNAs and age-associated neurodegeneration. Cell Res 22: 1218-1220, 2012.

16. Inukai S, de Lencastre A, Turner M and Slack F: Novel microRNAs differentially expressed during aging in the mouse brain. PLoS One 7: e40028, 2012.

17. Ungvari Z, Tucsek Z, Sosnowska D, et al: Aging-induced dysregulation of dicer1-dependent microRNA expression impairs angiogenic capacity of rat cerebromicrovascular endothelial cells. J Gerontol A Biol Sci Med Sci 68: 877-891, 2013.

18. Rao YS, Mott NN, Wang Y and Chung WC: MicroRNAs in the aging female brain: a putative mechanism for age-specific estrogen effects. Endocrinology 154: 2795-2806, 2013.

19. $\mathrm{Ma} \mathrm{L}$ and $\mathrm{Qu} \mathrm{L}$ : The function of microRNAs in renal development and pathophysiology. J Genet Genomics 40: 143-152, 2013.

20. Dumortier O and Van Obberghen E: MicroRNAs in pancreas development. Diabetes Obes Metab 14 Suppl 3: 22-28, 2012.

21. Ugalde AP, Español Y and López-Otín C: Micromanaging aging with miRNAs: new messages from the nuclear envelope. Nucleus 2: 549-555, 2011.

22. Roderburg C, Urban GW, Bettermann K, et al: Micro-RNA profiling reveals a role for miR-29 in human and murine liver fibrosis. Hepatology 53: 209-218, 2011.

23. Boon RA, Seeger T, Heydt S, et al: MicroRNA-29 in aortic dilation: implications for aneurysm formation. Circ Res 109: $1115-1119,2011$
24. Milewicz DM: MicroRNAs, fibrotic remodeling, and aortic aneurysms. J Clin Invest 122: 490-493, 2012.

25. Williams AE, Perry MM, Moschos SA and Lindsay MA: MicroRNA expression in the aging mouse lung. BMC Genomics 8: 172, 2007.

26. Wang Y, Scheiber MN, Neumann C et al: MicroRNA regulation of ionizing radiation-induced premature senescence. Int J Radiat Oncol Biol Phys 81: 839-848, 2011.

27. Schneider EL, Sternberg H, Tice RR, et al: Cellular replication and aging. Mech Ageing Dev 9: 313-324, 1979.

28. Kuhn HG, Dickinson-Anson H and Gage FH: Neurogenesis in the dentate gyrus of the adult rat: age-related decrease of neuronal progenitor proliferation. J Neurosci 16: 2027-2033, 1996.

29. Timchenko NA: Aging and liver regeneration. Trends Endocrinol Metab 20: 171-176, 2009.

30. Salminen A, Ojala $\mathbf{J}$ and Kaarniranta $\mathrm{K}$ : Apoptosis and aging: increased resistance to apoptosis enhances the aging process. Cell Mol Life Sci 68: 1021-1031, 2011.

31. Kwiecinski M, Noetel A, Elfimova N, et al: Hepatocyte growth factor (HGF) inhibits collagen I and IV synthesis in hepatic stellate cells by miRNA-29 induction. PLoS One 6: e24568, 2011.

32. Xiong Y, Fang JH, Yun JP, et al: Effects of microRNA-29 on apoptosis, tumorigenicity, and prognosis of hepatocellular carcinoma. Hepatology 51: 836-845, 2010.

33. Ma W, Xie S, Ni M, et al: MicroRNA-29a inhibited epididymal epithelial cell proliferation by targeting nuclear autoantigenic sperm protein (NASP). J Biol Chem 287: 10189-10199, 2012.

34. Wang B, Komers R, Carew R, et al: Suppression of microRNA-29 expression by TGF- $\beta 1$ promotes collagen expression and renal fibrosis. J Am Soc Nephrol 23: 252-265, 2012.

35. Cui Y, Su WY, Xing J, et al: MiR-29a inhibits cell proliferation and induces cell cycle arrest through the downregulation of p42.3 in human gastric cancer. PLoS One 6: e25872, 2011.

36. Lippi G, Steinert JR, Marczylo EL, et al: Targeting of the Arpc3 actin nucleation factor by $\mathrm{miR}-29 \mathrm{a} / \mathrm{b}$ regulates dendritic spine morphology. J Cell Biol 194: 889-904, 2011.

37. Pullen TJ, da Silva Xavier G, Kelsey G and Rutter GA: miR-29a and miR-29b contribute to pancreatic beta-cell-specific silencing of monocarboxylate transporter 1 (Mct1). Mol Cell Biol 31: 3182-3194, 2011.

38. Braconi C, Kogure T, Valeri N, et al: microRNA-29 can regulate expression of the long non-coding RNA gene MEG3 in hepatocellular cancer. Oncogene 30: 4750-4756, 2011.

39. Pekarsky Y, Santanam U, Cimmino A, et al: Tcl1 expression in chronic lymphocytic leukemia is regulated by miR-29 and miR-181. Cancer Res 66: 11590-11593, 2006.

40. Fabbri M, Garzon R, Cimmino A, et al: MicroRNA-29 family reverts aberrant methylation in lung cancer by targeting DNA methyltransferases 3A and 3B. Proc Natl Acad Sci USA 104: 15805-15810, 2007.

41. Kong G, Zhang J, Zhang S, et al: Upregulated microRNA-29a by hepatitis $B$ virus $X$ protein enhances hepatoma cell migration by targeting PTEN in cell culture model. PLoS One 6: e19518, 2011.

42. Wang CM, Wang Y, Fan CG, et al: miR-29c targets TNFAIP3, inhibits cell proliferation and induces apoptosis in hepatitis B virus-related hepatocellular carcinoma. Biochem Biophys Res Commun 411: 586-592, 2011.

43. Zong Y, Wang H, Dong W, et al: miR-29c regulates BACE1 protein expression. Brain Res 1395: 108-115, 2011.

44. Ding DP, Chen ZL, Zhao XH, et al: miR-29c induces cell cycle arrest in esophageal squamous cell carcinoma by modulating cyclin E expression. Carcinogenesis 32: 1025-1032, 2011.

45. Lin Y, Wu J, Chen $\mathrm{H}$, et al: Cyclin-dependent kinase 4 is a novel target in micoRNA-195-mediated cell cycle arrest in bladder cancer cells. FEBS Lett 586: 442-447, 2012.

46. Chen YQ, Wang XX, Yao XM, et al: MicroRNA-195 promotes apoptosis in mouse podocytes via enhanced caspase activity driven by BCL2 insufficiency. Am J Nephrol 34: 549-559, 2011.

47. Zhu H, Yang Y, Wang Y, et al: MicroRNA-195 promotes palmitate-induced apoptosis in cardiomyocytes by down-regulating Sirt1. Cardiovasc Res 92: 75-84, 2011.

48. Liu L, Chen L, Xu Y, et al: microRNA-195 promotes apoptosis and suppresses tumorigenicity of human colorectal cancer cells. Biochem Biophys Res Commun 400: 236-240, 2010.

49. Sekiya Y,Ogawa T, Iizuka M, et al: Down-regulation of cyclin E1 expression by microRNA-195 accounts for interferon- $\beta$-induced inhibition of hepatic stellate cell proliferation. J Cell Physiol 226: 2535-2542, 2011. 
50. Xu T, Zhu Y, Xiong Y, et al: MicroRNA-195 suppresses tumorigenicity and regulates G1/S transition of human hepatocellular carcinoma cells. Hepatology 50: 113-21, 2009.

51. Li D, Zhao Y, Liu C, et al: Analysis of MiR-195 and MiR-497 expression, regulation and role in breast cancer. Clin Cancer Res 17: 1722-1730, 2011.

52. Zhang QQ, Xu H, Huang MB, et al: MicroRNA-195 plays a tumor-suppressor role in human glioblastoma cells by targeting signaling pathways involved in cellular proliferation and invasion. Neuro Oncol 14: 278-287, 2012.

53. Zhu W, Zhu D, Lu S, et al: miR-497 modulates multidrug resistance of human cancer cell lines by targeting BCL2. Med Oncol 29: 384-391, 2012.

54. Yadav S, Pandey A, Shukla A, et al: miR-497 and miR-302b regulate ethanol-induced neuronal cell death through BCL2 protein and cyclin D2. J Biol Chem 286: 37347-37357, 2011.

55. Patel N, Tahara SM, Malik P and Kalra VK: Involvement of miR-30c and miR-301a in immediate induction of plasminogen activator inhibitor-1 by placental growth factor in human pulmonary endothelial cells. Biochem J 434: 473-482, 2011.

56. Zhao G, Zhang JG, Liu Y, et al: miR-148b functions as a tumor suppressor in pancreatic cancer by targeting AMPK $\alpha 1$. Mol Cancer Ther 12: 83-93, 2013.

57. Cimino D, De Pittà C, Orso F, et al: miR 148 b is a major coordinator of breast cancer progression in a relapse-associated microRNA signature by targeting ITGA5, ROCK1, PIK3CA, NRAS, and CSF1.FASEB J 27: 1223-1235, 2013.

58. Kim BM, Woo J, Kanellopoulou C and Shivdasani RA: Regulation of mouse stomach development and Barx1 expression by specific microRNAs. Development 138: 1081-1086, 2011.

59. Fang L, Deng Z, Shatseva T, et al: MicroRNA miR-93 promotes tumor growth and angiogenesis by targeting integrin- $\beta 8$. Oncogene 30: 806-821, 2011.

60. Du L, Schageman JJ, Subauste MC, et al: miR-93, miR-98, and miR-197 regulate expression of tumor suppressor gene FUS1. Mol Cancer Res 7: 1234-1243, 2009.

61. Kim YK, Yu J, Han TS, et al: Functional links between clustered microRNAs: suppression of cell-cycle inhibitors by microRNA clusters in gastric cancer. Nucleic Acids Res 37: 1672-1681, 2009.
62. Ivanovska I, Ball AS, Diaz RL, et al: MicroRNAs in the miR-106b family regulate $\mathrm{p} 21 / \mathrm{CDKN} 1 \mathrm{~A}$ and promote cell cycle progression. Mol Cell Biol 28: 2167-2174, 2008.

63. Li B, Shi XB, Nori D, et al: Down-regulation of microRNA $106 \mathrm{~b}$ is involved in p21-mediated cell cycle arrest in response to radiation in prostate cancer cells. Prostate 71: 567-574, 2011.

64. Hu S, Dong TS, Dalal SR, et al: The microbe-derived short chain fatty acid butyrate targets miRNA-dependent p21 gene expression in human colon cancer. PLoS One 6: e16221, 2011.

65. Cai K, Wang Y and Bao X: MiR-106b promotes cell proliferation via targeting RB in laryngeal carcinoma. J Exp Clin Cancer Res 30: 73, 2011.

66. Zhang Z, Tang H, Wang Z, et al: MiR-185 targets the DNA methyltransferases 1 and regulates global DNA methylation in human glioma. Mol Cancer 10: 124, 2011

67. Liu M, Lang N, Chen X, et al: miR-185 targets RhoA and Cdc42 expression and inhibits the proliferation potential of human colorectal cells. Cancer Lett 301: 151-160, 2011.

68. Imam JS, Buddavarapu K, Lee-Chang JS, et al: MicroRNA-185 suppresses tumor growth and progression by targeting the Six1 oncogene in human cancers. Oncogene 29: 4971-4979, 2010.

69. Weng Z, Wang D, Zhao W, et al: microRNA-450a targets DNA methyltransferase 3a in hepatocellular carcinoma. Exp Ther Med 2: 951-955, 2011.

70. Bao B, Rodriguez-Melendez R, Wijeratne SS and Zempleni J: Biotin regulates the expression of holocarboxylase synthetase in the miR-539 pathway in HEK-293 cells. J Nutr 140: 1546-1551, 2010.

71. Bao B, Rodriguez-Melendez R and Zempleni J: Cytosine methylation in miR-153 gene promoters increases the expression of holocarboxylase synthetase, thereby increasing the abundance of histone $\mathrm{H} 4$ biotinylation marks in HEK-293 human kidney cells. J Nutr Biochem 23: 635-39, 2012.

72. Funamizu N, Lacy CR, Parpart ST, et al: MicroRNA-301b promotes cell invasiveness through targeting TP63 in pancreatic carcinoma cells. Int J Oncol 44: 725-734, 2014. 